\title{
Developing a self-directed career guidance intervention for South African high school learners amidst severe COVID-19 restrictions
}

\begin{tabular}{|c|c|}
\hline \multicolumn{2}{|c|}{$\begin{array}{l}\text { Authors: } \\
\text { Michelle Jäckel-Visser }{ }^{1} \text { (D) } \\
\text { Stephan Rabie }{ }^{2} \text { (D) } \\
\text { Anthony V. Naidoo }{ }^{3} \text { (I) } \\
\text { Izanette van Schalkwyk }{ }^{3} \text { (D) } \\
\text { Francois J. van den Berg }{ }^{3} \text { (D) } \\
\text { Chantel Streicher }\end{array}$} \\
\hline $\begin{array}{l}\text { Affiliations: } \\
{ }^{1} \text { Department } \\
\text { Psychology, Fa } \\
\text { Economic and } \\
\text { Sciences, Stell } \\
\text { University, Ste } \\
\text { South Africa }\end{array}$ & $\begin{array}{l}\text { f Industrial } \\
\text { culty of } \\
\text { Management } \\
\text { enbosch } \\
\text { lenbosch, }\end{array}$ \\
\hline $\begin{array}{l}{ }^{2} \text { Department } \\
\text { and Mental H } \\
\text { of Health Scie } \\
\text { University of } \\
\text { Cape Town, So }\end{array}$ & $\begin{array}{l}\text { f Psychiatry } \\
\text { alth, Faculty } \\
\text { apes, } \\
\text { ape Town, } \\
\text { uth Africa }\end{array}$ \\
\hline $\begin{array}{l}{ }^{3} \text { Department } \\
\text { Faculty of Arts } \\
\text { Sciences, Stell } \\
\text { University, Ste } \\
\text { South Africa }\end{array}$ & $\begin{array}{l}\text { f Psychology, } \\
\text { and Social } \\
\text { enbosch } \\
\text { llenbosch, }\end{array}$ \\
\hline $\begin{array}{l}\text { Corresponding } \\
\text { Michelle Jäcke } \\
\text { mvis@sun.ac.z }\end{array}$ & $\begin{array}{l}\text { author: } \\
\text { l-Visser, } \\
\text { a }\end{array}$ \\
\hline $\begin{array}{l}\text { Dates: } \\
\text { Received: } 24 \\
\text { Accepted: } 22 \\
\text { Published: } 10\end{array}$ & $\begin{array}{l}\text { une } 2020 \\
\text { ct. } 2021 \\
\text { ec. } 2021\end{array}$ \\
\hline $\begin{array}{l}\text { How to cite th } \\
\text { Jäckel-Visser, } \\
\text { Naidoo, A.V., } \\
\text { I., Van den Ber } \\
\text { Streicher, C. (2 } \\
\text { Developing a s } \\
\text { career guidanc } \\
\text { for South Afric } \\
\text { learners amids } \\
\text { COVID-19 rest } \\
\text { Journal of Car } \\
\text { Development, } \\
\text { https://doi.org } \\
\text { v3i1.40 }\end{array}$ & $\begin{array}{l}\text { is article: } \\
\text { 1., Rabie, S., } \\
\text { an Schalkwyk, } \\
\text { g, F.J., \& } \\
021) . \\
\text { elf-directed } \\
\text { e intervention } \\
\text { an high school } \\
\text { t severe } \\
\text { ictions. African } \\
\text { 3(1), a40. } \\
/ 10.4102 / \text { ajcd. }\end{array}$ \\
\hline Read online: & \\
\hline 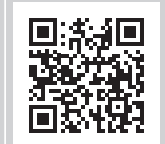 & $\begin{array}{l}\text { Scan this QR } \\
\text { code with your } \\
\text { smart phone or } \\
\text { mobile device } \\
\text { to read online. }\end{array}$ \\
\hline
\end{tabular}

Background: South African schools have been severely impacted by the coronavirus disease 2019 (COVID-19) pandemic in 2020. State-imposed restrictions to mitigate the spread of the infection have significantly limited direct interpersonal contact, curtailing the existing career guidance and counselling activities in schools. Crucially, in low-income settings, the social distancing regulations implied that in a year of increasing anxiety and uncertainty, many high school learners would have had to make important career-related decisions with limited or no tacit career guidance.

Objectives: In response to these challenges, this study developed a self-directed career guidance intervention to provide continued career guidance support for Grade 9 learners amidst the unfolding global pandemic.

Method: A cross-sectional mixed-methods design was employed to evaluate feasibility and acceptability of the intervention amongst a sample of 498 learners across eight high schools in the Cape Winelands district, Western Cape province, South Africa.

Results: Favourable quantitative results were obtained assessing learners' experiences of participating in the intervention and on the perceived impact of the intervention on their career preparedness. Participants reported a mean score of 41.25 (out of 50) for acceptability of the intervention. In addition, they reported a mean score of 17.1 (out of 20) for perceived impact of the intervention on their career preparedness. In terms of feasibility, qualitative findings revealed that the intervention improved learners' self-knowledge and career directionality.

Conclusion: The mixed-methods results confirm the feasibility and utility of implementing a self-directed career guidance intervention amongst secondary school learners. Whilst learners reported positive evaluations of the self-directed career guidance booklet, they also expressed the need for one-on-one or group engagement with the intervention content.

Keywords: career development; COVID-19; self-directed approach; career guidance intervention; high school learners.

\section{Introduction}

The role and provision of career guidance and counselling at secondary school level are critical in supporting young adolescents for taking initial steps in formulating their post-school study and career goals (Hartung, Porfeli, \& Vondracek, 2005; Watts \& Sultana, 2004). For many black South Africans, equality of opportunity and access to quality post-school education are often hampered by a lack of resources and the lingering legacy of apartheid (Albien \& Naidoo, 2018; Maila \& Ross, 2018). In low-income settings, external factors such as economic deprivation, high youth unemployment rates, lack of access to career services and resources, and absence of parental support severely undermine the career development process (Dube, 2019). This is the reality for many South African high school learners, who have to contend with limited support and access to services and resources as they face making important career-related decisions (Pillay, 2020; Rabie, Visser, Naidoo, Van den Berg, \& Morgan, 2021). One of the first career milestones for the South African high school learner is formally selecting the subjects in Grade 9 for the final phase of their secondary education (Grades 10-12). In the absence of adequate career guidance and counselling, these decisions are often made haphazardly or randomly (Akhurst \& Mkhize, 2006), without due consideration for the post-school career trajectories linked to this decision (Naidoo et al., 2019). Ill-considered subject choice decisions 
taken at this stage may limit or compromise study options after matriculating (Gottfredson, 2005; Streicher, 2020) for many learners.

Superimposed on these challenges, the sudden escalation of the highly infectious global coronavirus disease 2019 (COVID-19) pandemic in 2020 (World Health Organization [WHO], 2020a) resulted in emergency regulations, with the South African government instating strict lockdown measures (Ramaphosa, 2020) to limit the spread of the infection. In 2020, South African high schools were impacted with immediate extended school closures and were challenged to adapt to remote learning modalities. When schools reopened, many schools adopted a rotation system with half of each class attending school every alternate week to comply with social distancing regulations. These drastic measures resulted in limited direct teacher-to-learner contact and less time available to cover the normal curriculum via remote learning. Furthermore, existing career guidance activities were severely limited if not entirely curtailed given the restrictions of the pandemic (Ramrathan, 2020; Van Bruwaene, Mustafa, Cloete, Goga, \& Green, 2020).

In response to these emerging restrictions, the current study was forced to pivot and adapt its established delivery mode to a self-directed career guidance intervention aimed as assisting the Grade 9 high school learners in making informed decisions about their careers (Streicher, 2020). The self-directed intervention required the learner to take responsibility for their own learning and development by working through a manualised booklet (Streicher, 2021). This can promote a sense of agency and empowerment (Morris, 2019), with several research studies indicating that self-directed learning can positively enhance learners' career decision-making abilities (Briska \& Dislere, 2018; De Bruin \& Cornelius, 2014; Holland \& Rayman, 2013). The established project is a joint social impact collaboration between the Departments of Psychology and Industrial Psychology at Stellenbosch University (2020) and eight resource-constrained partner high schools within a $30-\mathrm{km}$ radius of the campus. The project utilises a studentbased service-learning approach to provide career guidance through psychometric assessments and guidance workshops. The project intentionally links academic modules in the postgraduate programmes of both the departments with a community engagement objective, whereby students are afforded the opportunity to apply their Career Psychology theoretical knowledge and practical skills in appropriate community settings. The project specifically targets Grade 9 learners, as this is a pivotal gateway year in which learners need to choose their school subjects for the senior high school phase (Streicher, 2021). See Naidoo et al. (2021) and Rabie et al. (2021) for a full description and evaluation of the established intervention.

Considering the emerging COVID-19 pandemic disruptions, the project had to revisitits established design to accommodate the COVID-19 'no-contact' requirement specified by both the Western Cape Education Department authorities and the university's Research Ethical Committee, yet still providing postgraduate students the opportunity to be involved albeit remotely with community engagement. A hybrid intervention was conceptualised incorporating a combination of selfdirected and electronic career resources. A self-directed interactive booklet, the Grade 9 Self-directed Career Guidance Booklet (SCGB) (2020), was developed with various selfassessment exercises designed to have Grade 9 learners explore their self-knowledge and various career-related attributes, including favourite subjects, hobbies, interests, achievements, role models and personality traits.

To supplement the self-directed manual, electronic resources were developed by postgraduate students and made available on a dedicated career website (https: / / careerguidanceproject. co.za), as well as on a YouTube channel with career-related videos. Supplementary resources were also provided as a hard copy resource kit for each school to ensure learners had access to the basic resources in the likelihood, they were not able to access the project's website. Albien and Naidoo (2016) advised that learner access to distance or remote learning platforms and resources cannot be assumed as most learners do not have smartphones or can afford data connectivity costs. Thus, learners from lower socio-economic communities (with attendant limited access to public libraries, smartphones, tablets and computers), face significant barriers to source information about the world of work. Poor access to career information can contribute to learners making uninformed subject choices at school without a clear career plan in mind (Maila \& Ross, 2018; Streicher, 2021). Several of the partner schools have functioning computer facilities, but these can only be accessed during school hours.

The SCGB (2020) was translated into Afrikaans, the home language of $60 \%$ of the learners in the eight partner schools. The booklets together with snack packs and an evaluation questionnaire were delivered to the schools in the third term when lockdown restrictions were lifted. Learners were incentivised to complete the booklet and to fill out an evaluation form as it was crucial to obtain feedback in order to improve the intervention given the uncertainty of the COVID-19 pandemic trajectory. An essay competition was also launched with a prize offered at each school for the best essay describing how the booklet assisted the learner's career development process. Survey data were subsequently gathered from the learners to assess the utility and impact of the self-directed approach adopted during the COVID-19 lockdown in the 2020 academic year.

\section{Objectives}

In order to address pertinent career development needs of Grade 9 learners in South Africa amidst the COVID-19 pandemic, the objectives of the study were:

- to adapt the conventional delivery format of the Grade 9 Career Guidance Intervention

- to develop a self-directed career guidance booklet to support Grade 9 learners with self-knowledge exploration 
and career-related resources to assist with making informed subject selection decisions

- to develop a hybrid career guidance intervention incorporating a self-directed booklet and electronic resources (website resources and informational videos)

- to gather cross-sectional data on the feasibility and acceptability of the self-directed intervention

- to gather cross-sectional, self-report qualitative data on the perceived impact of the self-directed intervention on career preparedness.

\section{Study design}

This study was conducted using a cross-sectional mixedmethods research design. For the quantitative component, a survey design was employed to obtain systematic feasibility and acceptability data on the intervention. For the qualitative component, a deductive qualitative survey design was employed to gather in-depth feasibility and acceptability data on the intervention from which themes were extracted.

\section{Setting}

This study was conducted in six low-income communities within a $30-\mathrm{km}$ radius from the campus. In particular, the intervention was implemented in eight quintile two schools catering for the poorest learners in the respective communities. The communities are characterised by high rates of poverty and unemployment, and attendant sequelae such as high crime rates and school attrition. Crucially, schools in these communities are often understaffed and under-resourced, with limited access to career guidance services and resources (Maree, 2010).

\section{Sample}

Participants were recruited by convenience sampling with universal inclusion. That is, the project approached the principals at the participating schools to extend invitations to all Grade 9 learners to inform them of the study. The learners received information leaflets detailing the study, and those who expressed interest and who provided parental consent forms and assented to participate were included in the study. The intervention was delivered to 1684 Grade 9 learners across the eight secondary schools, and a subsample of $n=498$ participants provided feedback on the intervention. This subsample constitutes the unit of analysis in this study. The mean age of the sample was 15.27 years (standard deviation [s.d.] = 0.792), ranging between 13 and 18 years of age. Most of the subsamples were female participants $(n=237 ; 47.5 \%)$, with 86 learners (17.3\%) not indicating their gender. The majority of the participants indicated Afrikaans as their home language (57.6\%), with 37 (7.4\%) English-speaking participants and 89 (17.9\%) isiXhosa-speaking participants. A total of $85(17.1 \%)$ participants did not indicate their home language.

\section{Intervention}

The Self-Directed Career Guidance intervention is an adaptation of Grade 9 Career Guidance Intervention reported by Naidoo et al. (2019). In response to the COVID-19 pandemic and related restrictions, the project team adapted the original format of the intervention into a hybrid intervention incorporating self-directed and virtual (online electronic) resources. In particular, the content delivered during the original group-based career guidance workshops was adapted into a self-directed career guidance booklet. The booklet (2020) included various self-complete exercises that were designed to assist Grade 9 learners explore knowledge-of-self pertaining to their career interests, personality traits, achievements and role models. The booklet also provided pertinent career related information regarding guidance in making school subject selection, ways of engaging with environmental challenges, and links to various career resources and local tertiary institutions. In addition, resources on study skills, motivation to succeed at school, setting goals in career planning and developing a career action plan were included in the booklet, based on recommendations made by life orientation teachers.

Crucially, for the first time, the booklet was developed in both English and Afrikaans to provide more learners with access to information in their home language (Streicher, 2020); an isiXhosa translation of the booklet has been subsequently published. Moreover, to ensure that the lack of contact-based workshops was not a hindrance to the intervention, the self-directed booklet was supplemented by various resources. The virtual resources included a project-specific career guidance website (https:// careerguidanceproject.co.za) and a YouTube channel (https:// www.youtube.com/channel/UCN7woMB9RARkDsvIQ4 Ta8iA) with career-related videos. The website included access to resources such as career, university, college, and bursary information, as well as a contact portal through which learners could ask questions related to their subject choices and future career. The website is regularly updated to provide learners with access to current news regarding bursaries, career guidance, subject choices, local and global opportunities, and inspirational stories. The project also created a YouTube channel and developed video content to supplement activities in the selfdirected booklet. Videos were created to share information related to self-knowledge, subject choices, developing a career action plan, general career guidance, and the world of work in South Africa.

These videos also addressed the second major challenge amidst the pandemic, providing postgraduate students with community engagement opportunities. These students were trained on the content of the booklet and asked to develop videos facilitating various components of the intervention. The videos were developed using the video editing programme, Powtoon (2021), which gave students volunteering on the project the creative freedom to develop interactive, visually stimulating video content using animated characters and voiceovers. In this way, students were provided opportunities to develop career resources for the partner schools. In total, the students developed 15 videos that are available on the project's website and YouTube channel. In addition to the website content, Life Orientation teachers at the participating schools were provided access to a hard copy and electronic resource kit that contains information regarding universities, colleges, 
service careers, and bursary opportunities. Moreover, teachers can utilise the information in both the resource kits to help guide learners in their career development. All supplementary resources were referenced in the SCGB (2020) to facilitate ease of access to and awareness of the materials for the participating learners.

\section{Data collection}

Data were collected upon completion of the intervention using a paper-and-pencil semi-quantitative evaluation form. This form was developed specifically for the purposes of this study to determine the efficacy of the adapted format and presentation of the intervention. The evaluation form consists of 10 questions regarding participants' experience in completing the self-directed intervention. Responses are given on a five-point Likert scale with 1 (strongly disagree) to 5 (strongly agree) rating categories, for example, 'I found completing this booklet quite an interesting exercise'. The 10 items measuring user evaluation of the SCGB were aggregated into a total score. The total score ranges between 10 and 50, and is interpreted on a continuum, with higher scores indicating more favourable experiences. In addition, participants were asked to rate four questions about the impact of the intervention on their career preparedness on a similar Likert scale, for example, 'I believe that I will be able to accomplish the career goals that I set for myself'. Similarly, items measuring the impact on career preparedness were computed into a total score. The total score ranges between 4 and 20, and is interpreted on a continuum, with higher scores indicating greater impact on career preparedness. Participants were also asked to complete five open-ended questions related to their evaluation of the intervention content and participating in the self-directed intervention, for example, '[w] hat was your favourite part of the booklet? Please also shortly describe why'. As an additional data source, learners were asked to write a self-reflective essay on their experience in completing the SCGB. At each school, a prize of South African Rand (ZAR)200.00 was awarded for the best essay.

\section{Data analysis}

For the quantitative component, the paper-and-pencil data were double entered into Microsoft Excel, a software programme used to organise numbers and data to perform formulas and functions. The data were imported into the Statistical Package for the Social Sciences (SPSS) Version 27, a software programme used for statistical analyses, for data cleaning. Data cleaning involved reviewing each case of entered data to identify any data entry errors and/or inconsistencies and rectifying these errors prior to data analysis. Once data cleaning was completed, each measure of the evaluation form was analysed by frequency analyses and descriptive statistics to ascertain participants' systematic feedback on the intervention. Moreover, these responses were collated into a total score to determine feasibility and acceptability of the intervention. For the qualitative component, the qualitative data (i.e. written responses to open-ended questions) were entered verbatim into Microsoft Word and imported into ATLAS.ti for analysis. ATLAS.ti is a softwarebased research management tool that can be used to code and analyse qualitative data. A deductive coding approach was applied to the data. This involved gaining familiarity with the dataset, using a combination of descriptive and values coding to gain an understanding of the nature of the data. Thereafter, line-by-line coding was applied to recognise the nuances, commonalities, and peculiarities within the dataset. A thematic analytical approach was applied to the data to identify recurring themes and subthemes (Braun \& Clarke, 2013).

\section{Ethical considerations}

Ethical clearance for the study was obtained from Stellenbosch University's Research Ethics Committee (SU/PN3072), from a public university in the Western Cape, as well as from the Western Cape Department of Education. Permission was obtained from the eight secondary schools in the Cape Winelands district. All the school principals and departmental heads were involved in the planning and implementation of the intervention. Prior to data collection, informed consent was obtained from the potential participants' caregivers, and written informed assent was obtained from the participants. All participants were informed that their participation was completely voluntary, and that they could withdraw from the study at any time. All data were anonymised for analysis.

\section{Results}

Favourable feedback was received on participants' experience completing the self-directed career guidance booklet. The mean scores on participants' experience completing the booklet ranged between 38.92 and 44.64, across the eight schools. A composite mean score of 41.25 (out of 50) was reported, scoring at the 70th percentile, and signifying highly positive experiences in completing the self-directed booklet. These scores are summarised in Table 1.

Similarly, participants reported positive feedback on the perceived impact of the intervention on their career preparedness. The mean scores of the perceived impact on career preparedness were relatively high, ranging between 16.37 and 17.98 with a composite mean score of 17.12 (out of 20) reported across the eight schools, scoring at the 75th percentile, and demonstrating a positive impact on career preparedness. These scores are summarised in Table 2.

TABLE 1: Participant feedback on booklet experience.

\begin{tabular}{lccl}
\hline School & $\boldsymbol{n}$ & Mean score & s.d. \\
\hline Cloetesville & 157 & 41.84 & 4.86 \\
Franschoek & 46 & 41.22 & 4.49 \\
Groendal & 14 & 43.00 & 2.82 \\
Makapula & 26 & 39.31 & 3.79 \\
Kayamandi & 44 & 40.61 & 6.93 \\
Kylemore & 11 & 44.64 & 3.64 \\
Rosendaal & 82 & 40.11 & 6.37 \\
Stellenzicht & 56 & 38.93 & 4.48 \\
\hline
\end{tabular}

Source: Streicher, C. (2020). An evaluation of the grade 9 self-directed career quidance intervention. Unpublished Honours Paper. Psychology Department, Stellenbosch University. s.d., standard deviation. 
TABLE 2: Participant feedback on perceived impact on career preparedness.

\begin{tabular}{lccl}
\hline School & $\boldsymbol{n}$ & Mean score & s.d. \\
\hline Cloetesville & 155 & 17.35 & 2.20 \\
Franschoek & 46 & 16.72 & 2.19 \\
Groendal & 14 & 17.93 & 1.40 \\
Makapula & 25 & 16.92 & 1.99 \\
Kayamandi & 43 & 16.37 & 2.58 \\
Kylemore & 11 & 17.55 & 1.69 \\
Rosendaal & 25 & 16.92 & 1.99 \\
Stellenzicht & 80 & 17.39 & 2.52 \\
\hline
\end{tabular}

Source: Streicher, C. (2020). An evaluation of the grade 9 self-directed career guidance intervention. Unpublished Honours Paper. Psychology Department, Stellenbosch University. s.d., standard deviation.

In addition to the quantitative feedback, participants' qualitative feedback on the self-directed career guidance intervention was explored. In total, four themes were identified in the data: Improved Self-Knowledge, Career Directionality, Booklet-related Challenges, and Additional In-person Support. The most notable theme identified in the data was participants' Improved SelfKnowledge. Several participants emphasised on how the selfdirected intervention enhanced their knowledge of personality type, career interests, and individual strengths and weaknesses. For instance, one participant shared that the booklet was:

'[V]ery interesting for me to learn more about myself. [These activities were] very helpful and used my personality to point me to a possible career I might one day want to do.' (L07, female, 15 years, Afrikaans, School8)

Other participants shared that the self-assessment activities included in the booklet 'helped me to get better insight about myself' and that these activities 'taught me more about myself and who and what I am'. This theme is best represented by the following quote:

'[The booklet] helped me to know who I really want to be when I grow up and it even led to the subjects that I can choose for Grade 10. This booklet strongly helped me to know what I want to be.' (L12, female, 15 years, Afrikaans, School8)

Crucially, the data identified the My Career Flower (Naidoo, 2011) as a salient activity that facilitated exploration of participants' self-knowledge. One of the participants (L17, female, 16 years, Afrikaans, School1) shared that the My Career Flower activity enabled her to 'set my own career goals and develop an action plan to realise my dream career'. Similarly, another participant (L02, female, no age data, Afrikaans, School8) shared the career flower helped me a lot and what I like about it, it showed a lot of interest. I write my dream jobs, my strengths and others [etc.]'.

The improved self-knowledge reported by participants appeared to contribute to the second major theme identified in the data, namely Career Directionality. A number of participants attributed the self-directed intervention and related improved self-knowledge to a better understanding of their future career path. One participant (L34, male, no age data, English, School7) asserted that he 'learned of what type of person I am. I now know which career I belong to', whilst another participant shared that booklet encouraged her to 'talk about the things I find interesting, and I also feel quite confident about my subject choice and what I want to do after school'. Another participant (L23, male, 15 years, is Xhosa, School2) asserted that upon completion of the booklet, he 'felt completely sure about my subject choices and what I want to do after school'.

Despite the reported benefits ascribed to the intervention, Booklet-related Challenges were identified as another pertinent theme. Some participants shared that completing the booklet 'took a lot of time' and at some schools 'there was too little time to complete everything'. A handful of participants also reported that 'certain sections weren't as easy to understand and some of the words were difficult to understand'. Similarly, some participants had 'to read some of the sections more than once' to understand how to complete the exercises. However, despite these challenges, the majority of the feedback received indicated that the 'booklet was very enjoyable' and participants could 'understand and read it clearly'.

The final theme identified in the data was participants' suggestions for Additional In-person Support. Although most participants reported that the self-directed booklet was helpful in aiding their subject choice and career decisionmaking, a few participants expressed the need for additional contact-based support. For instance, one participant (L11, male, 15 years, Afrikaans, School8) shared: 'Yes, although I got support from the booklet, I need someone with experience in the career that I want to pursue'. Similarly, another participant shared that:

' $[I]$ found which career I like but I have to choose one because they are not in the same field. I think I need someone who would tell me this career would be best for me.' (L20, female, 15 years, IsiXhosa, School7)

A male participant indicated that he is 'still unsure what I want to become' and he would like someone 'to explain which subjects I need to take if I'm unsure about what I want to do' (L13, male, 15 years, Afrikaans, School8). These excerpts may signify that for participants who are ambivalent or uncertain about their career path, individual counselling may be beneficial.

The project received valuable data in the form of the selfreflective essays submitted by the learners. In total, 10 essay submissions were received from four of the participating schools and an essay winner was selected at each school. The overarching theme identified in these self-reflective essays related strongly to the qualitative feedback received - completing the booklet provided the learners with better knowledge of self. One learner (L78, male, no age nor language data, School6) wrote 'I got to discover things I didn't know about myself' whilst another learner shared 'as I worked through the booklet, I learned so much about myself and my ability to do things' (L70, female, no age data, isiXhosa, School5). Another learner wrote that the booklet gave her 'more clarity about which subjects to choose for my specific career' which made her 'life so much easier with all the decisions I need to make 
for my future' (L108, female, no age data, Afrikaans, School3). Crucially, several participants wrote about how completing the self-directed booklet instilled a sense of hope for the future. One of the essay winners shared:

'[I] learned that one can rise above your circumstances and situation you find yourself in. I am motivated to work hard and get good marks so that I can proceed in my life.' (L44, female, no age, no language, School3)

These sentiments are corroborated by the following essay excerpt:

' $[E]$ ach and every one of us have different abilities and interests, not all of us can be doctors, but all of us can do something we love. Knowledge will forever be the key to our success.' (L35, female, no age nor language data, School7)

\section{Discussion}

In the wake of the COVID-19 pandemic, this study set out to establish the feasibility and acceptability of an intervention using a self-directed career guidance booklet to address career development needs of secondary school learners living in low-income communities. As such, the aim of the current study included the revisiting of the original format of the Grade 9 Career Guidance booklet (used in workshop sessions) with the view to design a self-directed format of the booklet to support the learners to work independently with the content, and to assess a hybrid intervention incorporating self-directed and electronic (virtual) resources. Learner quantitative survey data and qualitative responses to open-ended questions yielded valuable evaluative findings. The quantitative results showed the positive impact of the intervention on Grade 9 learners' career preparedness. The majority of participants reported that upon completion of the intervention, they were more confident in their abilities to achieve their goals and plans for their career after school. The qualitative findings shed light on the feasibility of the intervention by revealing that the intervention improved self-knowledge and career directionality.

Whilst the quantitative results confirm learners' satisfaction that the self-directed booklet was a valuable and sufficient resource in aiding their subject choice and career decisionmaking, the qualitative findings revealed their need for additional interpersonal contact-based support (that was not permitted under the prevailing COVID-19 restrictions). Although this finding could indicate the need for assistance related to uncertainties about the learners' career decisions and subject choice, we should not disregard the possible risks and deficits associated with restricted human contact. The need for interpersonal contact may be a cry for connection to engage with the heightened anxiety that was experienced because of the uncertainty of the pandemic (Sahoo et al., 2020). With the major disruption to their lives, learners are finding it quite difficult to make sense of the current limbo, uncertainty and what is happening in the world (Lombana-Bemudez et al., 2020). They are exposed to a myriad false information being forwarded on social media platforms related to COVID-19 transmission and precautionary measures. All these concerns can also lead to excessive worrying, fear and anxiety about contracting the infection and can create a sense of panic amongst teenagers who may be highly suggestible. In the broader scheme, career planning may seem an anachronism where more pressing family circumstances, concerns and uncertainty may be vying for their attention.

Overall, the findings clearly indicate that it is feasible and acceptable to implement a self-directed career guidance intervention amongst secondary school learners amidst a global pandemic. The booklet and the website may provide learners with a meaningful constructive way of investing their time and energy, and engaging with their lives. Valuable insight was also obtained pointing towards participants' need to engage with empathic adults in a safe space, especially in a time of social restrictions and heightened anxiety. This is particularly important as the participants of the current study cannot be viewed as 'invulnerable children' (see Wong \& Wong, 2012).

Apart from the numerous challenges associated with the global pandemic, Geinger, Roets and Vandenbroeck (2017) cautioned against the de-contextualising of youth development where adolescents are viewed as merely recipients or passive victims who are modelled by their parents and society, denying them their sense of autonomy. Clearly, the role of context influencing learners' career preparation and aspirations was of seminal importance (WHO, 2014) for this study conducted in 2020 amidst the coronavirus (COVID-19) disease pandemic (WHO, 2020b). The findings support the need to conceptualise career development within the broader sense of the learners' lives and their ecological context. The attention provided to contextualising the booklet, having it available in accessible language, adding local protagonists that the learners could identify with added to their receptivity of the booklet. Appiah, Wilson-Fadiji, Wissing and Schutte (2021) posited that interventions produce better results when they are '... practicable, convenient and directly relate to participants' circumstances' (p. 9).

Despite the significant barriers that adolescents, especially from lower socio-economic backgrounds, face to achieve optimal life chances (Bux, 2021; UNICEF, 2016) intensified by the numerous risks in such resource-restrained settings (Luthar, Lyman, \& Crossman, 2015), participants referred to their experience of a sense of direction, autonomy, connection and of hope for the future. This finding is significant, given the alarming youth unemployment rates in this country. Efforts need to be redoubled to provide career guidance resourcing at all high schools. Career guidance is crucial in preparing learners to make the best possible choices, thereby reducing the short- and long-term fallout that occurs with ill-considered decisions (Pillay, 2020).

\section{Conclusion}

The findings indicate that Grade 9 learners confirmed that it is feasible and acceptable to implement a self-directed 
career guidance intervention amongst high school learners living in low-income communities amidst a global pandemic. The hybrid intervention was found to be sufficient to provide support to assist high school learners make educational, training and occupational choices. Although these services were virtual rather than face-toface, adolescents benefitted from the career information and self-assessment activities and tools. These findings have important implications for similar resource-constrained settings that may not have ready access to in-person career guidance and counselling. Having functional school computer labs are imperative to give learners agency and access to internet-based resources to augment their selfdirected career development initiatives.

The current study has a few limitations. Firstly, although all participants were recruited from low-income communities, we used convenience sampling with universal inclusion. Therefore, we cannot exclude the possibility that the sample was under-representative, hence limiting the generalisability of the findings. Coronavirus disease-2019 restrictions extant in the schools at the time of data collection meant that applying uninform data collection methods had to be adapted, given the different circumstances in each school context. Incentives provided to learners to complete the evaluation survey may also have biased the data collected. Notwithstanding, the COVID pandemic circumstances provided a unique opportunity to adapt an existing career guidance intervention from a face-to-face format to a selfdirected format, with learners being able to work independently with the exercises and content. The COVID-19 pandemic also has provided a seminal reminder to consider career planning more holistically, as being integral to high school learners' well-being, and their need for directionality and wanting to live a life of meaning and purpose (Wong, 2020).

From the insights gained from the qualitative findings, it is recommended that future research explores how the selfdirected career guidance booklet can be effectively used as part of the Life Orientation curriculum. Group discussion of the various component of the booklet may help to expose learners to broader career ideas and knowledge and the support of their peers (Rabie et al., 2021). Also, whilst the self-directed booklet was supplemented by various resources, including - electronic resources (a dedicated career website) to ensure access to information for secondary school learners, we suggest that future research considers methods to train life orientation teachers to implement the booklet as part of the Life Orientation curriculum. Furthermore, the intervention should incorporate online contact with a career counsellor to provide direct online access to learners with their queries. Using video consultation rather than telephonic, email or SMS consulting is recommended to enhance the face-to-face or relating and interacting quality of the career guidance process, when direct contact is not possible.
The findings of this study hold important implications for similar resource-constrained settings that may not have ready access to in-person career guidance and counselling services. Self-directed resources and tools can play a valuable role in encouraging learner autonomy and agency. These resources are at best auxiliary enablers of the career exploration process but cannot replace the imperative of having access to adequate career guidance and face-to-face counselling services in place at all high schools in the country (Pillay, 2020). Self-directed career development resources cannot replace, substitute or fill the gap for this social justice imperative (Naidoo et al., 2019). Whilst the doors of learning have been opened to all learners, career guidance services at all schools should be part of that democratic education right and dispensation for all South African high school learners, more so in uncertain, unsettling times.

\section{Acknowledgements Competing interests}

The authors declare that they have no financial or personal relationships that may have inappropriately influenced them in writing this article.

\section{Authors' contributions}

M.J-V. led the conceptualisation, drafted the introduction and coordinated the writing process; A.V.N. drafted the theoretical section and edited the final draft; SR drafted the methodology and analysis section; I.v.S. and F.v.B. drafted the discussion section; C.S. conducted the literature review and assisted F.v.B. with the data collection.

\section{Funding information}

This research work received funding from the Rupert Educational Foundation and Stellenbosch University for the implementation of the programme reported in this study.

\section{Data availability}

Data sharing is applicable to this article, and data can be accessed from the first author on request.

\section{Disclaimer}

The views and opinions expressed in this article are those of the authors and do not necessarily reflect the official policy or position of any affiliated agency of the authors, and the publisher/s.

\section{References}

Akhurst, J., \& Mkhize, N.J. (2006). Career education in South Africa. In G.B. Stead \& M.B. Watson (Eds.), Career psychology in the South African context (2nd ed., pp. 139-153). Pretoria: Van Schaik.

Albien, A.J., \& Naidoo A.V. (2018). Barriers and enablers for career development among marginalized South African youth. In V. Cohen-Scali, J. Rossier, \& L. Nota (Eds.), New perspectives on career counseling and guidance in Europe (pp. 147164). Cham: Springer. 
Appiah, R., Wilson Fadiji, A., Wissing, M.P., \& Schutte, L. (2021). Participants' experiences and impressions of a group-based positive psychology intervention programme for rural adults in Ghana. International Journal of Qualitative Studies on Health and Well-Being, 16(1), 1891760. https://doi.org/10.1080/17482631.2021.1891760

Braun, V., \& Clarke, V. (2013). Successful qualitative research: A practical guide for beginners. London: Sage.

Briska, L., \& Dislere, V. (2018). Guidance model for promoting self-directed caree decision-making by secondary school students. In 14th International Scientific Conference: Rural Environment, Education, \& Personality Conference Proceeding (pp. 344-353). https://doi.org/10.22616/REEP.2018.042

Bux, D.B. (2021). Creative arts interventions to enhance adolescent well-being in low-income communities: An integrative literature review. Masters dissertation. North-West University: Potchefstroom.

De Bruin, K., \& Cornelius, E. (2014). Self-directed learning and career decision-making. Acta Academica, 43, 214-235.

Dube, T. (2019). Narrative identities: Voices of the unemployed youth in a low-income community in South Africa. Doctoral dissertation. Stellenbosch University.

Geinger, F., Roets, G., \& Vandenbroeck, M. (2017). Families with young children in times of economic downturn: Implications for social work practice. International Journal of Social Welfare, 27(3), 270-281. https://doi.org/10.1111/ijsw.12296

Gottfredson, L.S. (2005). Applying Gottfredson's theory of circumscription and compromise in career guidance and counseling. In S.D. Brown \& R.W. Lent (Eds.) Career development and counseling: Putting theory and research to work (pp. 71-100). Hoboken, NJ: John Wiley \& Sons, Inc.

Hartung, P.J., Porfeli, E.J., \& Vondracek, F.W. (2005). Child vocational development: A review and reconsideration. Journal of Vocational Behavior, 66(3), 385-419. https://doi.org/10.1016/j.jvb.2004.05.006.

Holland, J.L., \& Rayman, J.R. (2013). The self-directed search. In W.B. Walsh \& S.H. Osipow (Eds.), Advances in vocational psychology: Volume 1: The assessment of interests (pp. 55-82). Routledge.

Lombana-Bermudez, A., Cortesi, S., Fieseler, C., Gasser, U., Hasse, A., Newlands, G., \& $\mathrm{Wu}, \mathrm{S}$. (2020). Youth and the digital economy: Exploring youth practices, motivations, skills, pathways, and value creation. Youth and Media, Berkman Klein Center for Internet \& Society. Retrieved from https://cyber.harvard.edu/ publication/2020/youth-and-digital-economy

Luthar, S.S., Lyman, E.L., \& Crossman, E.J. (2015). Resilience and positive psychology In M. Lewis \& K.D. Rudolph (Eds.), Handbook of developmental psychopathology (pp. 125-140). New York, NY: Springer Science + Business Media.

Maila, P., \& Ross, E. (2018). Perceptions of disadvantaged rural matriculants regarding factors facilitating and constraining their transition to tertiary education. South African Journal of Education, 38(1), 1-12. https://doi.org/10.15700/saje.v38n1a1360

Maree, J.G. (2010). Career-story interviewing using the three anecdotes technique. Journal of Psychology in Africa, 20(3), 369-379. https://doi.org/10.1080/1433023 7.2010.10820388

Morris, T. (2019). Self-directed learning: A fundamental competence in a rapidly changing world. International Review of Education, 65(4), 633-653. https://doi. org/10.1007/s11159-019-09793-2

Naidoo, A.V. (2011). Career flower - Enhancing vocational self-awareness. Caree Development Group Activity. Unpublished manuscript. Stellenbosch University.

Naidoo, A.V., Visser, M., De Wet, M., Rabie, S., Van Schalkwyk, I., Boonzaier, M., ... Shirley, L. (2019). An early life design group based career guidance intervention for South African high school learners from low income communities. In J. Maree (Ed.), Innovating caree counselling theory, research, and practice (pp. 665-685). Cham, Springer.
Pillay, A.L. (2020). Prioritising career guidance and development services in postapartheid South Africa. African Journal of Career Development, 2(1), a9. https:// doi.org/10.4102/ajcd.v2i1.9

Powtoon Ltd. (2021). Powtoon. Retrieved from https://www.powtoon.com/

Rabie, S., Visser, M., Naidoo, A.V., van den Berg, F., \& Morgan, B. (2021). Beyond the individual: A group-based career development intervention implemented in resource-constrained schools in South Africa. Journal for Specialists in Group Work, 46(1), 48-61. https://doi.org/10.1080/01933922.2020.1856252

Ramaphosa, C. (2020). President Cyril Ramaphosa: Escalation of measures to combat Coronavirus COVID-19 pandemic. Speech Transcript. South African Government. Retrieved from https://www.gov.za/speeches/presidentcyril-ramaphosa-escalation-measures-combat-coronavirus-covid-19pandemic-23-mar

Ramrathan, L. (2020). School curriculum in South Africa in the Covid-19 context: An opportunity for education for relevance. Prospects, 51(1), 383-392. https://doi. org/10.1007/s11125-020-09490-1

Sahoo, S., Rani, S., Shah, R., Singh, A.P., Mehra, A., \& Grover, S. (2020). COVID-19 pandemic-related anxiety in teenagers. Indian Journal of Psychiatry, 62(3), 328-330. https://doi.org/10.4103/psychiatry.IndianJPsychiatry_327_20

SCGB. (2020). Grade 9 self directed career guidance booklet. A career guidance resource by the Departments of Industrial Psychology and Psychology, Stellenbosch University. Stellenbosch University, Stellenbosch.

Stellenbosch University. (2020). Grade 9 career guidance project. Retrieved from https://careerguidanceproject.co.za

Streicher, C. (2020). An evaluation of the grade 9 self-directed career guidance intervention Unpublished Honours Paper. Psychology Department, Stellenbosch University.

Streicher, C. (2021). Feasibility and acceptability of the self-directed career guidance project among grade 9 learners in the Cape Winelands. Master's thesis. Stellenbosch: Stellenbosch University.

Van Bruwaene, L., Mustafa, F., Cloete, J., Goga, A., \& Green, R.J. (2020). What are we doing to the children of South Africa under the guise of COVID-19 lockdown? South African Medical Journal, 110(7), 574-575

Watts, A.G., \& Sultana, R.G. (2004). Career guidance policies in 37 countries: Contrasts and common themes. International Journal for Educational and Vocational Guidance, 4(2-3), 105-122. https://doi.org/10.1007/s10775-005-1025-y

Wong, P.T.P. (2020). Existential positive psychology and integrative meaning therapy International Review of Psychiatry, 32(7-8), 565-578. https://doi.org/10.1080/09 540261.2020.1814703

Wong, P.T.P., \& Wong, L.C.J. (2012). A meaning-centered approach to building youth resilience. In P.T.P. Wong \& P.S. Fry (Eds.), The human quest for meaning: Theories, research, and applications (2nd ed., pp. 585-617). New York, NY: Routledge.

World Health Organization. (2014). Health for the world's adolescents: A second chance in the second decade. Retrieved from https://www.who.int/docs/default-source/ substance-use/1612-mncah-hwa-executive-summary.pdf?sfvrsn=c320d63b_2

World Health Organisation. (2020a, May 11). Virtual press conference on COVID-19 - 11 March 2020. Press release. Retrieved from https://www.who. int/docs/default-source/coronaviruse/transcripts/who-audio-emergenciescoronavirus-press-conference-full-and-final-11mar2020.pdf?sfvrsn= cb432bb3_2

World Health Organization. (2020b, June 30). Timeline of WHO's response to COVID-19. Retrieved from https://www.who.int/ 